\title{
Study of endogenous plant growth substances in Douglas fir I. Cytokinin analysis
}

\author{
N. Imbault ${ }^{1}$, P. Doumas ${ }^{2}$, C. Joseph ${ }^{1}$ and M. Bonnet-Masimbert ${ }^{2}$ \\ 1 Laboratoire des Composés Phénoliques, Université d'Orléans, BP 6769, 45067 Orléans Cedex \\ 02 , and \\ 2 INRA, Station d'Amélioration des Arbres Forestiers, Ardon, 45160 Olivet, France
}

\section{Introduction}

To ascertain the part played by a natural substance in a biological phenomenon, it is necessary to follow the endogenous evolution of this compound during the induction of the process. This is a real problem with plant growth substances (PGS). Indeed, their very low concentrations in tissues make PGS difficult to quantify. Because of their sensitivity and specificity, immunological methods have been adapted to the analysis of PGS and enable, in some cases, measurements at the level of a single organ, as reported for principally herbaceous species (Weiler, 1984). In this paper, some of their applications to the woody plant, Douglas fir (Pseudotsuga menziesii Mirb.), are presented: purification by immunoaffinity chromatography (IAC) and measurement by an enzymelinked immunosorbent assay (ELISA) or a radioimmunoassay (RIA).

\section{Materials and Methods}

\section{Material}

The study was performed on sexual buds of Douglas fir.

\section{Cytokinin isolation}

Cytokinins were extracted with $80 \%$ methanol in phosphate buffer $(\mathrm{pH} 7.2)$. After concentration, the extracts were passed through a diethylaminoethyl-cellulose column and purified either on an immunoaffinity (IA) column (as described below) or on an octadecylsilica one. Cytokinins were then separated by high-performance liquid chromatography (HPLC) using a reverse phase column (MacDonald et al., 1981) and measured either by UV absorption or by ELISA or RIA (as reported below).

\section{Immunological methods}

For IAC and EL.ISA procedures, monocional antibodies were raised against cytokinins conjugated to bovine serum albumin (MacDonald and Morris, 1985). IA columns of $1 \mathrm{ml}$ each contained equal amounts of anti-ribosylzeatin (anti-RZ) and anti-isopentenyladenosine (antiIPA) antibodies coupled to a cellulose matrix. With this mixture of antibodies, IAC was performed according to MacDonald and Morris (1985). Thus, the usual cytokinin bases and ribosides were recognized. ELISA was performed as described in Bataille et al. (1987); detection limit and range were $15 \mathrm{pg}$ and $20-5000$ $\mathrm{pg}$, respectively. RIA was done according to MacDonald et al. (1981) using polyclonal anticytokinin antibodies; defection limit and range here were, $50 \mathrm{pg}$ and $100-5000 \mathrm{pg}$, respectively. 

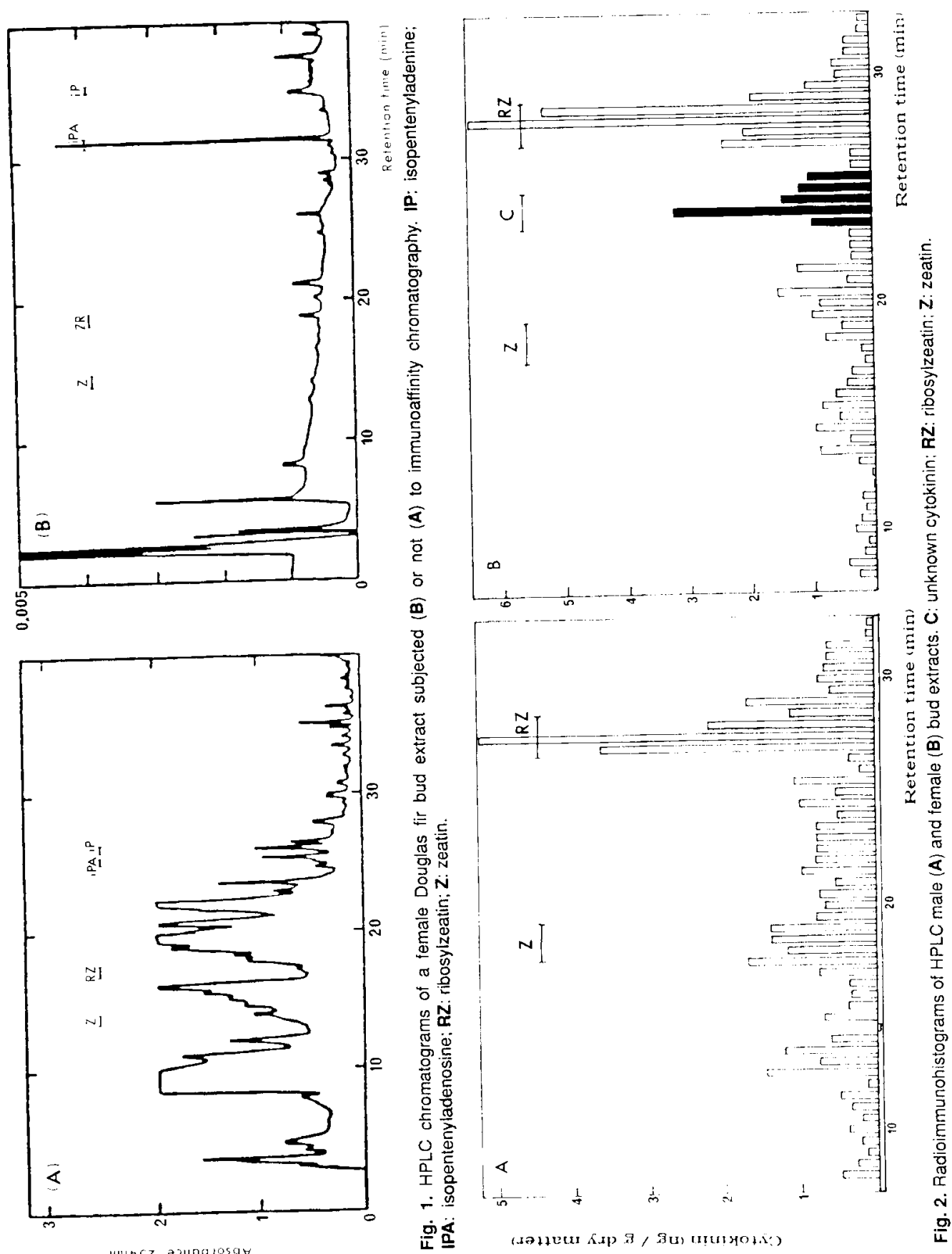


\section{Results}

Fig. 1 shows the HPLC chromatogram of one extract from a female bud of Douglas fir subjected to IAC (B) or not (A). IAC cleared the extract of UV absorbing compounds. Further cytokinin quantification performed by RIA on HPLC fractions demonstrated no significant losses of these PGS through IAC. Therefore, IAC, which retained only immunologically reactive compounds, acted as a selective filter enabling quantification by integration of the peaks.

In Fig. 2, radioimmunohistograms of HPLC male (A) and female (B) bud extracts are represented. A RZ-like substance exists in both male and female buds and quantities were very similar. Furthermore, a peak, called $\mathrm{C}$, which did not co-chromatograph with any cytokinin standard, was only present in female bud extracts. Thus, this measurement method made it possible to determine molecules other than the standard ones. These results were confirmed by ELISA.

\section{Discussion and Conclusion}

To study the evolution of cytokinins in Douglas fir tissues, immunological methods can be used. Because of their sensitivity, they need only low quantities of plant material. However, the detection limit by UV absorption (254 $\mathrm{nm}$ ) after IAC was only 1-5 ng. For small samples, the more sensitive ELISA or RIA (15 or $50 \mathrm{pg}$ ) could be used. Thus, despite the inherent difficulties of the woody material, PGS analysis is possible and practical at the organ level, where physiological processes occur. One application of this possibility was illustrated by the study of Imbault et al. (1988), which showed the intervention of IP and IPA in Douglas fir flowering.

\section{References}

Bataille A., Dournas P., Zaerr J.B. \& Morris R.O. (1987) Comparison of ELISA and RIA for cytokinin analysis. Plant Physiol. 83 (suppl.), 96

Imbault N., Tardieu I., Joseph C., Zaerr J.B. \& Bonnet-Masimbert M. (1988) Possible role of isopentenyladenine and isopentenyladenosine in flowering of Pseudotsuga menziesii: endogenous variations and exogenous applications. Plant. Physiol. Biochem. 26, 289-295

MacDonald E.M.S. \& Morris R.O. (1985) Isolation of cytokinins by immunoaffinity chromatography and analysis by high-performance liquid chromatography-radioimmunoassay. Methods Enzymol. 110, 347-358

MacDonald E.M.S., Akiyoshi D.E. \& Morris R.O. (1981) Combined high-performance liquid chromatography-radioimmunoassay for cytokinins. J. Chromatogr. 214, 101-109

Weiler E.W. (1984) Immunoassay of plant growth regulators. Annu. Rev. Plant Physiol. 35, 85-95 